\title{
Research Status of Guangdong-Hong Kong-Macao Greater Bay Area
}

\author{
Zijiao Hu \\ Jinan University, Guangzhou, China \\ Email: Betterme8623@163.com
}

How to cite this paper: Hu, Z.J. (2019) Research Status of Guangdong-Hong KongMacao Greater Bay Area. Open Journal of Social Sciences, 7, 275-283. https://doi.org/10.4236/jss.2019.72021

Received: December 24, 2018

Accepted: February 25, 2019

Published: February 28, 2019

Copyright $\odot 2019$ by author(s) and Scientific Research Publishing Inc. This work is licensed under the Creative Commons Attribution International License (CC BY 4.0).

http://creativecommons.org/licenses/by/4.0/

\section{cc) (i) Open Access}

\begin{abstract}
In the context of global opening and the era of the Greater Bay Area, as a strategic fulcrum of the "Belt and Road" and an important form of regional development in the Pearl River Delta (PRD), Guangdong-Hong Kong-Macao Bay Area is an institutional arrangement that is in line with China's national conditions in the process of reform and opening up. Based on the domestic and international research results of the Bay Area, this article reviews the literature of the PRD and Guangdong-Hong Kong-Macao Bay Area, and relative researches in formation mechanism, evaluation system, development momentum, development model and so on. The current research is characterized by multidisciplinary and single content, and there are also many problems, such as emphasis on macro-economy and lack of empirical results. In the future, the focus and difficulty of the study should be the empirical analysis of micro subject within Bay Area.
\end{abstract}

\section{Keywords}

Bay Area, City Cluster, Development, Pearl River Delta

\section{Introduction}

Guangdong, Hong Kong and Macao have been cooperating for a long time. The cooperation between the three places has been the foundation of the PRD regional development. The proposal of the Guangdong-Hong Kong-Macao Greater Bay Area marks that the cooperation of the three parts has become the national agenda, and come into a total new scope-spatial cooperation. This pattern will help to promote the sharing of opportunities between cities, and it will be significant to the regional innovation network of PRD. The development of the Greater Bay Area will reduce the spatial distance between cities and increase the efficiency of inter-city cooperation in a multi-center PRD. As the frontier of 
reform and opening up and an important engine of economic growth, Guangdong-Hong Kong-Macao Bay Area is one of the important areas where China's innovation elements and resources are highly concentrated. It's the most mature area in the bay area of China, with excellent geographical conditions, abundance in capital, high openness, and already has the basic conditions to become a world-class bay area [1]. Awareness of the significance and benefit of technologies related to bay area has attracted a growing research attention. Thus, it's essential to measure the sharply increasing literature on the bay area.

\section{Study of Bay Area}

The Bay Area, geographically, is a region consisting of a bay or a number of connected bays, harbors, and neighboring islands. Nowadays, the most developed and competitive urban agglomerations are concentrated in the coastal bay area, such as the Tokyo Bay Area, the New York Bay Area, and the San Francisco Bay Area, which are recognized as the world's three major Bay Areas. It can be said that the Bay Area has become an important growth pole driving the global economic development and a leader in leading technological change. The economic effect derived from this is called the "Bay Area Economy" [2].

\subsection{Formation Mechanism}

Li believed that the formation of the "Bay Area Economy" requires five conditions: a strong industrial cluster, a strong economic core, a broad economic hinterland, a sound economic transportation network and a large number of international leading talents, and cross-border collaboration [3]. Referring to the condition of the well-developed bay area in the world, Yu believed that the superior geographical conditions of three sides of the land, the long coastline, and the economic hinterland, as well as the numerous port cities with the ability to preferentially absorb foreign investment, are the premise basis for the formation of the Bay Area [4]. And Wu summarized the development momentum of the bay area economy as basic power, endogenous power and exogenous power [5].

\subsection{Evaluation System}

Based on land area, regional GDP, industrial structure, innovation advantage, financial industry, and labor quality, $\mathrm{Lu}$ evaluated the competitive landscape of the four major Bay Areas in Shenzhen and Hong Kong. They built a four-dimensional evaluation system to measure the development level of the Bay Area-economic scale, efficiency, openness, and innovation. It was found that there is still a big gap between the Shenzhen-Hong Kong Bay Area and the other three major Bay Areas. The key point of promoting the economic development of the Bay Area was to develop regional characteristics, and promote institutional innovation [6]. Taking Shenzhen as the research object, Qi selected 30 secondary indicators from five dimensions: innovation radiation, open guidance, factor aggregation, interconnection and basic support to construct the economic evaluation index 
system of Shenzhen Bay Area. In their view, it was in a period of rapid development and had great potential for development [7].

\subsection{Foreign Experience}

In the research of the Tokyo Bay Area, Tetsuya Akiya-ma constructed a land use model, conducted a regression analysis of the planning of the Tokyo Bay Area Government. The evolution of the economic development model of the Tokyo Bay Area was summarized as three stages: "Green Belt + New City", "One Polar Concentration" and "Multi-Heart Multi-Core" [8].

With regard to the successful experience of the New York Bay Area, Lei believed that the region has formulated and implemented the strategy of innovation-driven development, which has played a dual role of the government and the market. At the same time, it promoted industrial transformation, improved urban infrastructure, and focused on education and personnel training [9]. In some scholar's point of view, the massive inflow of international funds, especially the mature European capital market in the 19th century, provided a large amount of funds for the construction of the canal and railway system, laying the foundation for the construction of the New York Bay Area infrastructure [10].

Regarding the development of the San Francisco Bay Area, Volberding focused on the relationship between the San Francisco Bay Area and the rise of China's economy in the context of globalization. It was believed that in the past 10 years, ports, high-tech and green technology have played an important role in the relationship between the two [11]. Alex Schafran studied the three interrelated factors of population, policy and capital, measured how they affect the economic development of the San Francisco Bay Area through multiple scales [12]. NP Makarem studied the special role of social networks in the economic development of the Bay Area [13].

\section{Study of Pearl River Delta}

Since the concept of the PRD has been proposed, many scholars have been paying attention to and studying the development of this region. As time goes by, the research literature in this area has gradually increased, there are more and more the content involved, new problems have appeared in the region of PRD. These problems not only reflect the development feature of the PRD in different periods, but also promote some practical points of view which are conductive to the economic and social development of the region.

\subsection{Development Momentum}

Based on multi-temporal satellite images data and GIS, Ding and Wang quantitatively analyzed the expansion patterns and characteristics of industrial production space in the PRD urban agglomeration, and found that the driving forces varied in different development stages-policy factors, economic globalization, regional urbanization, and technological progress and innovation promoted the 
evolution and reconstruction of industrial production space in the PRD [14]. Zou and Han constructed a theoretical framework of the relationship between foreign direct investment and economic growth by panel data of 9 cities from the PRD from 1999 to 2012. They concluded that compared with the quantity, the quality of foreign investment can promote the economic growth of the PRD [15].

\subsection{Development Model}

Consistent with $\mathrm{Xu}$ and others, most scholars believed that the economic development model of the PRD was mainly composed of two aspects: on the one hand, it relied on geographical advantages, took "Three-plus-one" trading-mix enterprises and "three-capital enterprises" as the carrier of the formation of a representative export-oriented economic pattern; on the other hand, the market system of the PRD presented the obvious characteristics of "internal and external linkage" and "two-way integration" in the development, it formed a typical extensive economic growth model of "pre-store and post-factory" [16]. In addition, Zhou pointed out that the economic development of the PRD urban agglomeration has been dependent on three aspects: export-oriented development model, labor-intensive industries and government-oriented urbanization [17].

Because of the different points of view, some scholars held different views. Starting from the spatial system and development model, $\mathrm{Xu}$ pointed out six key points in the following: growth pole-driven, dot-line connect, network in economic zone, hierarchical transformation of industry, experiment of special zone, and economic-ecological harmony development type [18]. Yao considered that there were two other models in the PRD-fragmented and integrated economy [19].

\subsection{Development Trend}

Based on Social Network Analysis, Feng and others discussed functional polycentricism of the Zhujiang River Delta region, and found that intercity rail traffic flow functional relation of the region had a high level of functional polycentricism, while the connection between East and west wings was obviously insufficient. With the advancement of intercity rail transit construction and the development of regional integration, the region of the multifunctional center will tend to be mature [20]. Yang also believed that the central bank of the Pearl River estuary was more concentrated than the western, and the core area was superior to the marginal area. Therefore, in the future, it's necessary to enhance the urban-rural development and transformation of the marginal areas of the "Guangfo-Shenguan" core area, form a stable " $\mathrm{A}$ " type spatial structure, and gradually interweave from polycentricism and development axle bands to form agglomeration zones [21].

For the future development of the PRD urban agglomeration, Wang and Zhou believed that it was necessary to take the innovative development strategies: 
"Digital PRD", “Greater PRD”, “Core PRD” and "Integration of the PRD” [22]. When studying the polycentricism competition model, Zhang found that it was showing a trend of linkage and integration development [23].

\section{Study of Guangdong-Hong Kong-Macao Bay Area}

Guangdong-Hong Kong-Macao Bay Area has become a hot issue in domestic strategic planning and economic research. At present, the main research on this area not only competes with the international mature bay area, but also explores and draws on its practical experience. Most of them focus on the significance, regional relationship and functional orientation, construction advantages and conditions, disadvantages and obstacles, cooperation model exploration and strategic choices, etc. Here we focus on the following two aspects for discussion.

\subsection{Functional Positioning}

Shenzhen was the first city to propose the "development of the Bay Area Economy" in the name of the local government. Therefore, many scholars have proposed the role of Shenzhen's leading and hub [24]. The Foreshore coastline was the focal point for future urban development [25], some scholars have proposed the concept of "dual-core" bay area construction in Guangzhou and Hong Kong [26]. Wu and Zhou summarized the experience of Shenzhen, Zhuhai and Shantou in layout optimization, core function, port hub and innovative development interchange since 2010 [27]. On the basis of cluster analysis, Chen took port container throughput as main index to classify the port, and built a key indicator model that affected port localization and development, and put forward a development model of "one heart, one body, two wings", namely took Shenzhen as its core port, the three hub ports of Shenzhen, Hong Kong and Guangzhou as major ports, and local important ports as wings in the east and west [28].

\subsection{Pattern Exploration}

For the well-established coordination mechanism, Yang proposed that the "primary task" was to find common interests of Guangdong-Hong Kong-Macao, establish a new language system, and form a think tank for full exchange [29]. In addition, Chen believed that attention should be paid to the construction of regional planning, regulatory governance and collaborative development mechanisms, which can provide guarantees for the promotion of economic, social, scientific, ecological and other fields [30]. Guo held the view that we should pay attention to the role of non-governmental organizations in cross-border cooperation, while exerting the power of various cooperative entities [31].

In terms of strategy, Zuo took marine transportation and maritime trade as strategic focus, it was necessary to strengthen marine strategic industries and marine economic cooperation [32]. In terms of industry selection, Deng's point of view was to build a modern service industry such as finance and technology consulting services in Hong Kong, turn gaming industry into sightseeing tour- 
ism in Macao, strengthen investment and deepen opening up in Guangdong Pilot Free Trade Zone [33].

In the aspect of optimizing the innovation environment and building a regional collaborative innovation system, $\mathrm{Wu}$ proposed to encourage and support social capital to set up regional venture capital funds to achieve a superposition of capital functions [34]. Wu believed that it was significant to promote the construction of two pilot zones for financial services in SME and nongovernmental investment innovation, and promote the transformation of private capital into investment capital, and to connect emerging industries, connect private enterprises to the capital market [35]. At the same time, Deng's point of view was to speed up the construction of research institutions and experimental bases that met the requirements of innovative industries, and to establish a mechanism for the introduction and sharing of high-level talents worldwide, such as implementing the policy of the "elite program" to explore and build "talent + projects" and "innovation + incubation" and other entrepreneurial models [36].

In the study of environmental improvement and green development in the Bay Area, Chen and others proposed to formulate marine ecological protection plans, optimize the ecological layout, and balance water and pollution control, to create special ecological livable leisure bay area in Hong Kong-Macao [37]. By assessing the cooperation between Hong Kong and Shenzhen during the 12th Five-Year Plan period, Zhang put forward the strategy of Hong Kong-Shenzhen cooperation during the 13th Five-Year Plan period in the context of the construction of the Guangdong-Hong Kong-Macao Bay Area comprehensively: exploring the establishment of a cross-border governance mechanism and statistical system, improving the efficiency of factor mobility, creating an innovation platform, promoting intergovernmental coordination of East-West integration and social affairs, training civil servants along the Maritime Silk Road, improving the level of international arbitration business, promoting the development of the marine economy and participating the formulation of international standards and rules actively [38].

\section{Conclusions}

The development and construction of Guangdong-Hong Kong-Macao Bay Area has become a hot spot in the field of academic and practical research, and a wealth of research results provide theoretical support and decision-making reference for further research in the Bay Area. Relevant research shows the following characteristics: in terms of research breadth, it has gradually expanded from the economic field to the political, social, legal, and cultural fields; in the case of research methods, it is not limited to theoretical research and qualitative conceptual analysis; the results of empirical testing using mathematical models began to appear.

However, there is no unified definition of the bay area economy at present. Also, there are differences in the definition of the scope of the Guangdong-Hong 
Kong-Macao Bay Area. Secondly, most of the existing researches start from the macro level, and analyze the development conditions, process or problems of the whole bay area through qualitative methods. There are few research results at the micro level, or we can say that there is almost none. Moreover, the majority of the research results are normative and predictive; the production of the application of mathematical models for measurement and empirical testing is still few.

In view of the shortcomings of existing research, it is necessary to clarify the direction and key issues of further research. To grasp the development and construction of the Greater Bay Area accurately, we must form a unified understanding of its connotation and extension first. The problem of game interaction between regions, competition and balance in cities, industrial clusters and differentiation within the bay area, and the issue of collaborative innovation among enterprises are also the focus of the future. Besides, we should tap the regularity of economic activities in the bay area and make monographic study in combination with multi-disciplines, which will help enrich the theory of regional cooperation, industrial economy and bay area. Last but not the least, we can combine field investigation with pilot data, and make more empirical research in the future.

\section{Conflicts of Interest}

The author declares no conflicts of interest regarding the publication of this paper.

\section{References}

[1] Yao, S.M., et al. (2016) New Perspectives on Urban Agglomerations in China.

[2] Lin, G.Q. and Xu, G.L. (2017) Development of Foreign Bay Areas and Its Implication to China. Journal of Shenzhen University (Humanities \& Social Science), 34, 25-31.

[3] Li, R. (2015) Development Experience and Enlightenment of International Famous "Bay Area". Port Economy, 9, 5-8.

[4] Yu, S.Q. (2016) Domestic and International Experience of Bay Area Economy. Fujian Finance, 6, 42-45.

[5] Wu, F.L., Tao, Y.T. and Shen, Y. (2015) Research on the Dynamic Mechanism of Economic Development in the Bay Area-International Cases and Enlightenment. Science \& Technology Progress and Policy, 32, 31-35.

[6] Lu, Z.G., Pan, F. and Yan, Z.K. (2015) Global Bay Area Economic Comparison and Comprehensive Evaluation Research. Science \& Technology Progress and Policy, 11, 112-116.

[7] Qi, L.M. (2016) Proposals on Developing Economic Index Monitoring System in the Bay Area of Shenzhen. Globalization, 6, 72-84.

[8] Arai, T. and Akiyama, T. (2004) Empirical Analysis for Estimating Land Use Transition Potential Functions-Case in the Tokyo Metropolitan Region. Computers Environment \& Urban Systems, 28, 65-84. https://doi.org/10.1016/S0198-9715(02)00043-1

[9] Lei, J. (2015) Analysis and Research on the Bay Area Economy. Practice and Theory 
of Sezs, 2.

[10] Shen, Y. and Ma, Z.X. (2017) Constructing the New Pattern of Opening Policy Led by Bay Area Economy: An Empirical Analysis Based on the Degree of Opening in the Guangdong-HK-Mac Bay Area. The Journal of Shanghai Administration Institute, 1 .

[11] Volberding, P. (2011) Engaging Regions in Globalization: The Rise of the Economic Relationship between the San Francisco Bay Area and China. Berkeley Undergraduate Journal, 23, 2.

[12] Schafran, A. (2013) Origins of an Urban Crisis: The Restructuring of the San Francisco Bay Area and the Geography of Foreclosure. International Journal of Urban \& Regional Research, 37, 663-688. https://doi.org/10.1111/j.1468-2427.2012.01150.x

[13] Makarem, N.P. (2013) Perceptions, Relations and Regional Economic Development: A Case Study of the Bay Area and Southern California. Dissertations \& Theses-Gradworks.

[14] Ding, J. and Wang, K.Y. (2018) Spatio-Temporal Evolution of Industrial Production Space and its Driving Mechanisms in Pearl River Delta Urban Agglomeration. Geographical Research, 37, 53-66.

[15] Zou, J.H. and Han, Y.H. (2013) Transformation of Foreign Investment Introduction Modes, Quality of FDI and Environment Pollution: Empirical Evidence from $9 \mathrm{Ci}$ ties in Pearl River Delta. Journal of International Trade, 7, 147-157.

[16] Xu, Y., Tao, C.Q. and Ding, H. (2015) An Empirical Analysis on the Coupling of Regional Industry Innovation and Industry Upgrading: A Case of the Pearl River Delta Region. Science Research Management, 36, 109-117.

[17] Zhou, C.S., Jing, W.F. and Shi, C.Y. (2015) Development Strategy of the Pearl River Delta Urban Agglomeration under the Current Socioeconomic Situation. Progress in Geography, 34, 302-312.

[18] Xu, D.H. (2010) Analysis of Economic Development Model and Path Innovation in the Pearl River Delta Region. Jiangsu Commercial Forum, 6, 153-155.

[19] Yao, H.S. and Xu, X.Q. (2009) Fragmented Economy, Integrated Economy or Incomplete Integrated Economy?-A Discussion on Regional Development of the Pearl River Delta. Tropical Geography, 3, 241-244.

[20] Feng, C.C., Xie, D.X. and Ma, X.G. (2014) Functional Polycentricism of the Urban Region in the Zhujiang River Delta Based on Intercity Rail Traffic Flow. Scientia Geographica Sinica, 34, 648-655.

[21] Yang, R., Xu, Q. and Li, L.T. (2016) Spatial Urban-Rural Transformation and Its Driving Factors in the Pearl River Delta Region. Geographical Research, 35, 2261-2272.

[22] Wang, S.G. and Zhou, Y.Z. (2002) Integrated Frame Research for Resources \& Environment in Megalopolises and Regional Sustainable Development: Case Study on Pearl River Delta. China Population, Resources and Environment, 12, 52-57.

[23] Zhang, J.G. (2008) From the Polycentric Competition to the United Integration: Thinking on the Transformation Model of the City Group's Development of the Pearl River Delta. Urban Problems, 1, 34-39.

[24] Chen, R.H. (2017) The Role of "Shenzhen-Zhongshan Channel" in the Economic Development of the Pearl River Delta Port. Practice and Theory of Special economic zones, 1, 114-117.

[25] Chen, N., Chen, K.S. and Fang, D.Q. (2017) Relationship between Mixed-Use and Urban Elements Size in City Central District: The Enlightenment of Singapore Ma- 
rina Bay Mode. Urban Planning International, 32, 96-103.

[26] Chen, D.N., Zheng, T.X. and Deng, C.Y. (2010) Research on the Economic Cooperation of Guangdong, Hong Kong, Macao in the "Bay Area" of Pearl River Estuary. Economic Geography, 30, 1589-1598.

[27] Wu, K.H. and Zhou, Y.H. (2015) The Path Choice of Guangdong Special Economic Zone under the New Situation. Guangdong Economy, 6, 58-63.

[28] Chen, C.M. (2016) Empirical Analysis of Port Group Positioning in the Guangdong-Hong Kong-Macau Big Bay Area. Journal of Shenzhen University (Humanities \& Social Sciences), 33, 32-35.

[29] Yang, G.S. (2017) To Find Common Ground for the Interests of Guangdong, Hong Kong and Macao. New Economy, 1, 17.

[30] Chen, W.H. (2009) World Urban Network in the Process of Globalization: The Concept and Development of the "Pearl River Delta" Metropolis. Forward Position in Economics, 1, 13-35.

[31] Guo, C. (2017) Co-Creating the Guangdong-Hong Kong-Macao Greater Bay Area, and Comparing with the World Super Bay Area. Environmental Economy, 2, 70-73.

[32] Zuo, X.A. (2017) The Mechanism Innovation of Guangdong-Hong Kong-Macao Cooperation that Harmoniously Develop with the Strategy of "Belt and Road". Special Zone Economy, 1, 11-14.

[33] Deng, J.N. (2016) Research on the Innovation Driven Path of Industrial Upgrade in Guangdong. South China Journal of Economics, 6, 114-120.

[34] Wu, Z. (2016) Guangdong-Hong Kong-Macao Greater Bay Area: Deepening Cooperation of Pan-Pearl River Delta Region. Ningbo Economy, 5, 20.

[35] Wu, W.R. (2015) Vigorously Develop the Economy of the Bay Area and Strive to Build a Modern Port City. Policy Outlook, 10, 13-16.

[36] Deng, Z.X. (2014) Shenzhen Free Trade Area's Construction under Bay Area Economy Development Strategy. Special Zone Economy, 12, 15-17.

[37] Chen, D.N., He, Y.M. and He, J.F. (2011) Low Carbon Economy and Coordinated Development Mechanism of Quality Bay Area. Lingnan Journal, 3, 94-97.

[38] Zhang, Y.G. (2015) On Advancing Shenzhen-Hong Kong Cooperation under the Framework of the Maritime Silk Road. China Opening Herald, 5, 29-33. 